\title{
Stimulated Phosphorylation of ERK in Mouse Kidney Mesangial Cells is Dependent Upon Expression of Cav3.1
}

\author{
Sudha Priya Soundara Pandi \\ University of Southampton \\ Michael J. Shattock \\ King's College London \\ Bruce M. Hendry \\ King's College London \\ Claire C. Sharpe ( $\nabla$ claire.sharpe@kcl.ac.uk) \\ King's College London
}

\section{Research Article}

Keywords: calcium channels, CRISPR-cas9, mesangial cell, ERK1/2, glomerulonephritis

Posted Date: September 28th, 2021

DOl: https://doi.org/10.21203/rs.3.rs-784562/v1

License: (c) (i) This work is licensed under a Creative Commons Attribution 4.0 International License. Read Full License 


\section{Abstract}

Background: T-type calcium channels (TTCC) are low voltage activated channels that are widely expressed in the heart, smooth muscle and neurons. They are known to impact on cell cycle progression in cancer and smooth muscle cells and more recently, have been implicated in rat and human mesangial cell proliferation. The aim of this study was to investigate the roles of the different isoforms of TTCC in mouse mesangial cells to establish which may be the best therapeutic target for treating mesangioproliferative kidney diseases.

Methods: In this study, we generated single and double knockout (SKO and DKO) clones of the TTCC isoforms $\mathrm{Ca}_{\sqrt{ }} 3.1$ and $\mathrm{Ca}_{\sqrt{ }} 3.2$ in mouse mesangial cells using CRISPR-cas9 gene editing. The downstream signals linked to this channel activity were studied by ERK1/2 phosphorylation assays in serum, PDGF and TGF- $\beta 1$ stimulated cells. We also examined their proliferative responses in the presence of the TTCC inhibitors mibefradil and $\mathrm{TH} 1177$.

Results: We demonstrate a complete loss of ERK1/2 phosphorylation in response to multiple stimuli (serum, PDGF, TGF- 31 ) in Cav3.1 SKO clone, whereas the Cav3.2 SKO clone retained these phosphoERK1/2 responses. Stimulated cell proliferation was not profoundly impacted in either SKO clone and both clones remained sensitive to non-selective TTCC blockers, suggesting a role for more than one TTCC isoform in cell cycle progression. Deletion of both the isoforms resulted in cell death.

Conclusion: This study confirms that TTCC are expressed in mouse mesangial cells and that they play a role in cell proliferation. Whereas the $\mathrm{Ca}_{\mathrm{V}} 3.1$ isoform is required for stimulated phosphorylation of ERK1/2, the $\mathrm{Ca}_{\mathrm{v}} 3.2$ isoform is not. Our data also suggest that neither isoform is necessary for cell proliferation and that the anti-proliferative effects of mibefradil and TH1177 are not isoform-specific. These findings are consistent with data from in vivo rat mesangial proliferation Thy 1 models and support the future use of genetic mouse models to test the therapeutic actions of TTCC inhibitors.

\section{Background}

Mesangial cells (MCs) in the glomeruli of the kidney are essential in maintaining the structural integrity of the glomerular capillary network[1]. In healthy adult kidneys, MCs remain in a quiescent state with a cell renewal rate of $<1 \%$ per day, as shown by autoradiography[2]. With various stress stimuli, including increases in blood pressure and blood sugar, MCs show aberrant proliferation. The uncontrolled MC proliferation can induce extracellular matrix (ECM) accumulation in the glomeruli, leading to glomerulosclerosis[3-5]. These features are recognised as a critical element in the pathogenesis of chronic kidney disease (CKD) secondary to many glomerular diseases, including diabetic nephropathy and IgA nephropathy.

The proliferation of $\mathrm{MC}$ is tightly regulated by various mitogenic stimuli including platelet derived growth factor (PDGF), PI3/AKT and tyrosine kinases[6-9]. In addition to this, the influx of $\mathrm{Ca}^{2+}$ via calcium 
channels appears to be involved in the regulation of $\mathrm{MC}$ proliferation. Alongside the different types of high voltage-gated calcium channels including $\mathrm{P} / \mathrm{Q}$ type, N-type, R-type, and L-type channels are the low voltage-gated T-type calcium channels (TTCC)[10]. It has been recognised for decades that calcium channel blockers can impact MC proliferation through mechanisms beyond L-type inhibition [11]. The specific target of these actions is uncertain, though they are unlikely to be P/Q-type, N-type or R-type calcium channels as there is no evidence of their expression in MC. TTCC on the other hand, are expressed in human and rat MC and are sensitive to inhibition by the TTCC blocker TH1177 in vitro and in vivo in the Thy 1 nephritis rat model[12]. Also, the knockdown of TTCC in human and rat MC has been shown to inhibit proliferation[12,13]. TTCC exhibit a similar structure to that of LTCC but differ in kinetics and activation threshold[10]. The blockade of TTCC also exhibits anti-proliferative properties in vascular and pulmonary arterial smooth muscle cells[14, 15] and human cancer cells[16]. In aortic smooth muscle cells, T-type calcium currents are predominantly present in the $\mathrm{G} 1$ phase and the synthesis phase of the cell cycle[14]. There are three isoforms of TTCC including Cav3.1 $\left(\mathrm{a} 1_{\mathrm{G}}\right), \mathrm{Ca}_{\mathrm{V}} 3.2\left(\mathrm{a} 1_{\mathrm{H}}\right)$ and $\mathrm{Ca} \mathrm{V}_{\mathrm{V}} 3.3\left(\mathrm{a} 1_{\mathrm{I}}\right)[10]$. To date, the role of specific TTCC isoforms in MC proliferation is not well studied. Additionally, there are no known reports available that show the presence of TTCC in mouse MC.

As no selective and specific small molecule inhibitors of TTCC isoforms exist, we aimed to investigate the expressions of TTCC isoforms in mouse MC in vitro and the impact of deletion of specific TTCC isoforms on cell proliferation and phosphorylation of ERK. We have, therefore, developed single and double knockouts ( $\mathrm{SKO}$ and DKO) of $\mathrm{Ca}_{\mathrm{V}} 3.1$ and $\mathrm{Ca}_{\mathrm{V}} 3.2$ by using the clustered regularly interspaced short palindromic repeats (CRISPR)/ CRISPR associated protein 9 (Cas9) gene editing system. We have also examined the stimulated phosphorylation of ERK1/2 in $\mathrm{Ca}_{\mathrm{V}} 3.1$ and $\mathrm{Ca}_{\mathrm{V}} 3.2 \mathrm{SKO} \mathrm{MC}$ clones as compared to WT cells and evaluated proliferation of $\mathrm{Ca}_{\mathrm{V}} 3.1$ and $\mathrm{Ca}_{\mathrm{V}} 3.2 \mathrm{SKO} \mathrm{MC}$ with and without non-selective TTCC blockers (mibefradil and TH1177).

\section{Methods}

\section{Cell culture}

Mouse mesangial cells (SV40 MES13) purchased from ATCC (Virginia, United States) were maintained in a 3:1 solution of Dulbecco's modified Eagle's medium (DMEM) (Invitrogen, Paisley, UK) and F-12 (Invitrogen). The medium was supplemented with $5 \%$ fetal bovine serum (FBS), $14 \mathrm{mM} \mathrm{HEPES,} 100 \mathrm{IU} / \mathrm{ml}$ penicillin, $100 \mu \mathrm{g} / \mathrm{ml}$ streptomycin, and $2.5 \mu \mathrm{g} / \mathrm{ml}$ amphotericin (Invitrogen). Cultured cells were maintained at standard cell culture condition at $37^{\circ} \mathrm{C}$ with $95 \% \mathrm{O}_{2}$ and $5 \% \mathrm{CO}_{2}$.

\section{Calcium channel inhibitors}

Mibefradil (Sigma Aldrich, Dorset, UK) and verapamil (Sigma Aldrich) were made from $10 \mathrm{mM}$ stock solutions in distilled water and stored at $4^{\circ} \mathrm{C}$, and every two months, fresh stock solutions were prepared. TH1177 was a kind gift from Dr Lloyd Gray, University of Virginia, Charlottesville, Va., USA. TH1177 was prepared from a $10 \mathrm{mM}$ stock solution in $100 \%$ ethanol and stored at $-20^{\circ} \mathrm{C}$ 


\section{Serum, PDGF and TGF- $\beta 1$ stimulation}

MES13 cells were seeded at $3 \times 10^{5}$ cells in $35 \mathrm{~mm}$ dishes with $1 \% \mathrm{FBS}$ for $48 \mathrm{~h}$. At $48 \mathrm{~h}$, cells were cultured in varied conditions: $0 \%$ FBS, $20 \%$ FBS, or $20 \mathrm{ng} / \mathrm{ml} \mathrm{PDGF-BB}$ and $10 \mathrm{ng} / \mathrm{ml}$ TGF- $\beta 1$ (R\&D Systems, Minneapolis, MN) and vehicle control [TGF- $\beta 1$ buffer- $4 \mathrm{mM} \mathrm{HCl}$ plus $0.1 \%$ BSA, pH3] for 24,48 and $72 \mathrm{~h}$ time points. Cells were harvested for RNA extraction at the end of each time point. The medium was removed and washed with PBS and $350 \mu$ of RLT buffer with beta-mercaptoethanol was used to lyse the cells. The RNA extraction was carried out using the RNeasy Mini Kit (Qiagen Ltd, Crawley, UK) by following the manufacturer's instructions.

\section{Reverse transcriptase- polymerase chain reaction (RT-PCR)}

cDNA was synthesised from $2 \mu \mathrm{g}$ of RNA using high capacity RNA to cDNA synthesis kit (Applied biosystems, Massachusetts, USA) in the $20 \mu$ reaction mix. RT-PCR amplification was carried out from 5 $\mu \mathrm{l}$ of cDNA using Dream Taq polymerase (Fischer Scientific, Loughborough, UK) using a thermocycler. The PCR amplification was carried out with an initial denaturation of $95^{\circ} \mathrm{C}$ for $3 \mathrm{~min}, 35$ cycles of denaturation $95^{\circ} \mathrm{C}$ for $30 \mathrm{~s}$, annealing Tm- 5 for $30 \mathrm{~s}$, extension $72^{\circ} \mathrm{C}$ for $1 \mathrm{~min}$ and final extension $72^{\circ} \mathrm{C}$ for 5 min. The RT-PCR primers are listed in Suppl. Table S1.

\section{CRISPR-cas9 plasmids}

plenti-CRISPR-cas9-gRNA for $\mathrm{Ca}_{\mathrm{V}} 3.1 / \mathrm{Ca}_{\mathrm{V}} 3.2$ was purchased from GenScirpt, New Jersey, USA. The plasmid contained a plentiCRISPRv2.0 backbone cloned with cas 9 , ampicillin, bleomycin, puromycin selection markers, and 20 nucleotides of the gRNA sequence complementary to exon 4 of Cacna1G and exon 6 of Cacna1H gene under the control of U6 promoter (Suppl. Fig. S2a-b).

\section{Transfection, antibiotic and clonal selection}

plenti-CRISPR-cas9-gRNA for $\mathrm{Ca}_{\sqrt{ }} 3.1 / \mathrm{Ca}_{\mathrm{V}} 3.2$ plasmids were used to generate stable knockouts which were transfected into MES13 cells using lipofectamine 3000 (Thermo fisher Scientific, Massachusetts, USA). Briefly, $6 \times 10^{5}$ cells were seeded in 6 well plates overnight in the antibiotic-free growth medium. The following day, for SKO generation, $5 \mu \mathrm{g}$ of plenti-CRISPR-cas9-gRNA for $\mathrm{Ca}_{\sqrt{ }} 3.1$ or $\mathrm{Ca}_{\sqrt{ }} 3.2$ plasmids and for DKO generation, 2.5ug each of plenti-CRISPR-cas9-gRNA for $\mathrm{Ca}_{\sqrt{ }} 3.1$ and $\mathrm{Ca}_{\mathrm{V}} 3.2$ were transfected by lipofection, and the medium was changed after $6 \mathrm{~h}$. Post $72 \mathrm{~h}$ of transfection, complete growth medium with $2 \mu \mathrm{g} / \mathrm{ml}$ of puromycin was added for antibiotic selection. The cells resistant to puromycin post $72 \mathrm{~h}$ antibiotic selection were trypsinised and sub-cultured to the new six-well plate and the second round of antibiotic selection was carried out using puromycin to minimise the contamination of untransfected cells. Although the cells were sorted with a selection marker, there remained a possibility of a mixed population of cells with a variable length of base-pair deletion of 1-19 nucleotides. Hence, the knockout cells were subjected to single-cell clonal selection by serial dilution starting with 500 cells in 96 -well plates. The SKO clones were picked, expanded and confirmed at the genomic level by Sanger sequencing and confirmed at the translational level by Western blot. This second round of puromycin selection 
resulted in too few cells to achieve single cell clonal selection for the DKO clones and expansion for Western blotting, hence DKO cells from the first round of antibiotic selection went through clonal selection in the conditional medium. The survived clones were sent for Sanger sequencing alone.

\section{Genomic DNA extraction, PCR and Sanger sequencing}

MES13 control cells and $\mathrm{Ca}_{\sqrt{ }} 3.1, \mathrm{Ca}_{\sqrt{ }} 3.2 \mathrm{SKO}$ and DKO clones were subjected to genomic DNA extraction by using the QIAamp DNA extraction kit (Qiagen Ltd, Crawley, UK), following the manufacturer's instructions. The genomic DNA was quantified in a Nanodrop, and $100 \mathrm{ng}$ of DNA was amplified by using Dream Taq polymerase and primers spanning the gRNA sequence region in $20 \mu \mathrm{l}$ reaction mix. The primer list is detailed in Suppl. Table S1. The PCR products were cleaned using the ExoSAP-IT Express PCR product clean-up kit (Thermo Fisher Scientific). The PCR product was preceded to Sanger sequencing by GATC Biotech, Ebersberg, Germany.

\section{MTS assay}

MES13 cells and SKO clones of $\mathrm{Ca}_{\mathrm{V}} 3.1$ and $\mathrm{Ca}_{\mathrm{V}} 3.2$ treated with or without calcium channel blockers (mibefradil and TH1177) were subjected to a microculture tetrazolium (MTS) assay (Promega, Southampton, UK) to measure the cell number. Briefly, MES13 cells, $\mathrm{Ca}_{\vee} 3.1$ and $\mathrm{Ca}_{\vee} 3.2 \mathrm{SKO}$ clones were subjected to serum deprivation in $1 \%$ FBS for $48 \mathrm{~h}$. Cells were seeded into 96 -well plates at a density of 5000 cells per well and incubated with varied concentration of mibefradil and $\operatorname{TH} 1177(0,5,10$ and 20 $\mu \mathrm{M})$ in $5 \% \mathrm{FBS}$. Absorbance at $492 \mathrm{~nm}$ was measured at 48 , and $72 \mathrm{~h}$ in a microplate reader.

\section{Signal transduction evaluation}

MES13 and SKO clones of Ca 3.1 and Ca 3.2 were seeded at $6 \times 10^{5}$ cells per well in 6 well plates and left overnight. The cells were serum deprived to $1 \%$ FBS for $48 \mathrm{~h}$. At $48 \mathrm{~h}$, the cells were stimulated for 30 min with either: $5 \%$ FBS, $20 \mathrm{ng} / \mathrm{ml}$ PDGF $+1 \%$ FBS or $10 \mathrm{ng} / \mathrm{ml} \mathrm{TGF-} \beta 1+1 \%$ FBS.

Similarly, MES13 cells alone were seeded at $6 \times 10^{5}$ cells per well in 6 well plates and left overnight. The cells were serum deprived to $1 \%$ FBS for $48 \mathrm{~h}$. At $44 \mathrm{~h}$, the cells were treated with $5 \mu \mathrm{M}$ mibefradil $+1 \%$ FBS and at $48 \mathrm{~h}$, the cells were stimulated with $5 \% \mathrm{FBS}, 20 \mathrm{ng} / \mathrm{ml} \mathrm{PDGF}+1 \% \mathrm{FBS}$ and $10 \mathrm{ng} / \mathrm{ml}$ of TGF$\beta 1+1 \%$ FBS for $30 \mathrm{~min}$.

The medium was removed immediately after 30 min stimulation, washed with PBS, and the cells were lysed with RIPA buffer with protease and phosphatase inhibitor (Sigma). The lysate was scraped off from the plates and incubated on ice for $30 \mathrm{~min}$ with intermittent vortexing. The lysates were centrifuged for $14,000 \mathrm{rpm}$ at $4^{\circ} \mathrm{C}$ for $20 \mathrm{~min}$. The supernatant from the lysate was transferred to new labelled tubes and stored at $-80^{\circ} \mathrm{C}$. The experiments were repeated three times.

\section{Western Blot}


The protein concentration was quantified by BCA assay (ThermoFisher Scientific), and 20-40 $\mu \mathrm{g}$ of protein was separated in $8 \%$ PAGE gel. The proteins were transferred to a nitrocellulose membrane at 35 $\mathrm{V}$ for $3 \mathrm{~h}$ for $\mathrm{Ca}_{\mathrm{V}} 3.1$ and $\mathrm{Ca}_{\mathrm{V}} 3.2$ and $100 \mathrm{~V}$ for $1 \mathrm{~h}$ for $\mathrm{pERK} 1 / 2$. The protein transfer was confirmed by Ponceau staining, and the blots were washed and incubated with $5 \%$ non-fat milk (Sigma) for $1 \mathrm{~h}$. The blots were incubated with primary antibodies: $\mathrm{Ca}_{\mathrm{V}} 3.1$ (1:1000) (Alomone, Jerusalem, Israel) and $\mathrm{Ca}_{\mathrm{V}} 3.2$ (1:500) (Alomone), pERK1/2 (1:5000) (Cell signaling, London, UK), total ERK1/2 (1:5000) (cell signaling) and beta-actin (1:5000) (Abcam, Cambridge, UK) overnight at $4^{\circ} \mathrm{C}$. The following day, the blots were washed thrice with $1 \times$ TBS $+0.1 \%$ Tween 20 (TBS-T) for 10 min and then incubated with anti-rabbit secondary antibody conjugated with horse radish peroxidase for $1 \mathrm{~h}$ at room temperature. The blots were washed thrice with $1 \times$ TBS-T and incubated with ECL substrate (Fisher scientific) for 5 min and exposed to X-ray film. In order to probe for total ERK1/2 and beta-actin, the blots were stripped with stripping buffer (Sigma) for 30 min at RT under dark. Protein band density was quantified using Image Studio Lite software.

\section{Statistics}

All data were tested for normality and no difference in the variances between groups was detected using the Shapiro-Wilk test. Parametric variables were analysed using a One-Way Analysis of Variance (for multiple group comparisons) with a post hoc Bonferroni test or Two-Way Analysis of Variance with post hoc Tukey test. $p<0.05$ is considered as statistical significance. Statistical analyses were performed using Prism software version 8.0 (Graph-Pad Software, San Diego, CA).

\section{Results}

\section{Pharmacological T-type calcium channel inhibition is anti- proliferative in wild-type mouse mesangial cells}

The expression of Cav3.1, Cav3.2 and Cav 3.3 in wild type (WT) mouse MC (MES13) was confirmed by reverse transcriptase PCR followed by agarose gel electrophoresis (Suppl. Fig. S1). Figure 1 shows that there was a dose-dependent inhibition of MC cell proliferation with TTCC inhibitors mibefradil (Fig. 1a) and TH1177 (Fig. 1b) with an apparent ED50 of 5-10 $\mu \mathrm{M}$. This was in contrast to no inhibition of cell proliferation with the LTCC blocker verapamil at up to $20 \mu \mathrm{M}$ (Fig. 1c). These data are consistent with published work on human and rat MC[12,13] and confirm a role for TTCC but not LTCC in mouse MC stimulated proliferation.

Blocking of T-type calcium channels in mouse mesangial cells inhibits the phosphorylation of ERK1/2

MAPK signaling plays a major role in regulating mesangial cell proliferation $[17,18]$. Hence stimulated phosphorylation of ERK1/2 was evaluated in the WT control cells (MES13) treated with 5\% FBS, PDGF or transforming growth factor-beta 1 (TGF- $\beta 1$ ) with or without TTCC blockers mibefradil and TH1177. 
Figure 2 shows that stimulated phosphorylation of ERK $1 / 2$ is clearly reduced by mibefradil. $\mathrm{TH} 1177$ also inhibits the pERK1/2 response in 5\% FBS, TGF- $\beta 1$ and PDGF (Fig. 3).

\section{$\mathrm{Ca}_{\mathrm{v}} 3.1$ and $\mathrm{Ca} \mathrm{v}_{\mathrm{v}} 3.2$ deletion in mouse mesangial cells by CRISPR-Cas9 gene editing}

CRISPR-cas9-Ca 3 3.1/ $\mathrm{Ca}_{\mathrm{V}} 3.2$ transfection with single-cell clonal selection allowed us to obtain cells with $\mathrm{Ca}_{\vee} 3.1, \mathrm{Ca}_{\vee} 3.2 \mathrm{SKO}$ as determined by PCR and Western blot. There was no compensatory change seen in the other TTCC isoform in each case. Details of the methodology and verification of knockdown are shown in the Supplementary Material and Supplementary Figures S2-S4. DKO cells fail to survive, hence

only sequencing was performed to confirm the knockout, suggesting knockout of both the TTCC isoforms is lethal to cell survival. This also suggests that expression of at least one of the two isoforms is needed for cell proliferation.

\section{Knockout of $\mathrm{Ca}_{\mathrm{v}}$ 3.1, not $\mathrm{Ca}_{\mathrm{v}} 3.2$ inhibits the phosphorylation of pERK1/2}

To evaluate the role of the different TTCC isoforms $\mathrm{Ca}_{\mathrm{V}} 3.1$ and $\mathrm{Ca}_{\mathrm{V}} 3.2$ on the activation of the MAPK pathway, the SKO clones were treated with $5 \%$ FBS, PDGF or TGF- $\beta 1$ and pERK $1 / 2$ versus total ERK $1 / 2$ assayed by Western blot. The level of stimulated pERK1/2 protein in the $\mathrm{Ca}_{\mathrm{V}} 3.1 \mathrm{SKO}$ clone was significantly reduced in 1\% FBS, 5\% FBS, PDGF and TGF- $\beta 1$ compared to WT control cells (Fig. 4a and b). Conversely, the level of stimulated pERK1/2 in the Cav3.2 SKO clone was the same as in WT control cells in all the treatment conditions (Fig. $4 \mathrm{c}$ and d). This suggests that the activation of the pERK $1 / 2$ by a variety of pro-proliferative stimuli is mediated via Cav3.1 with Cav3.2 playing little or no role.

\section{Knockout of $\mathrm{Ca}_{\mathrm{v}} 3.1$ or $\mathrm{Ca}_{\mathrm{v}} 3.2$ results in a significant but small reduction in cell proliferation}

The $\mathrm{Ca}_{\vee} 3.1$ and $\mathrm{Ca}_{\vee} 3.2 \mathrm{SKO}$ clone were used to evaluate the biological significance of these TTCC isoforms in cell proliferation. We evaluated the effect of the TTCC blockers on the stimulated proliferation of $\mathrm{Ca}_{\mathrm{V}} 3.1$ and $\mathrm{Ca}_{\mathrm{V}} 3.2 \mathrm{SKO}$ clones as compared to WT cells.

In the absence of TTCC blockade, both $\mathrm{Ca}_{\sqrt{ }} 3.1$ and $\mathrm{Ca}_{\sqrt{ }} 3.2 \mathrm{SKO}$ clones exhibited a small but significant reduction in serum-stimulated proliferation at $48 \mathrm{~h}$ compared to WT control cells (Fig. 5a and c). These differences were not apparent at $72 \mathrm{~h}$ (Fig. $5 \mathrm{~b}$ and d). Both the $\mathrm{Ca}_{\sqrt{ }} 3.1$ and $\mathrm{Ca}_{\mathrm{V}} 3.2 \mathrm{SKO}$ clones remained sensitive to inhibition of proliferation by mibefradil and TH1177 as seen in Fig. 5, where the apparent ED50 for inhibition is broadly similar in the WT control and SKO cells. There was a tendency for the $\mathrm{Ca}_{\mathrm{V}} 3.1 \mathrm{SKO}$ clone to show reduced proliferation in the presence of low doses TTCC inhibitor compared with WT cells.

\section{Discussion}

In this study, we have demonstrated that i) mouse MC express TTCC and are sensitive to two TTCC inhibitors: mibefradil and TH1177. However, MC are insensitive to the LTCC inhibitor, verapamil; ii) The 
TTCC isoforms $\mathrm{Ca}_{\mathrm{V}} 3.1$ and $\mathrm{Ca}_{\mathrm{V}} 3.2$ were successfully knocked out in mouse MC by CRISPR-cas9 gene editing, creating viable single-cell TTCC isoform SKO clones; iii) $\mathrm{Ca}_{\sqrt{ }} 3.1$ SKO, but not Ca 3.2 SKO inhibits the serum, PDGF and TGF- $\beta 1$ stimulated phosphorylation of ERK1/2; iv) The effect of $\mathrm{Ca}_{\mathrm{V}} 3.1$ SKO on pERK1/2 is similar to the actions of TTCC blockers (mibefradil and TH1177) in WT cells; v) Knock out of either $\mathrm{Ca}_{\mathrm{V}} 3.1$ or $\mathrm{Ca}_{\sqrt{ }} 3.2$ alone does not alter the anti-proliferative effects of mibefradil or TH1177 and has minimal effects on stimulated cell proliferation, whereas knock out of both isoforms completely inhibits proliferation.

TTCC and their role in MC proliferation have been reported in a few studies. Findings in rat and human $M C$ have shown that only $\mathrm{Ca}_{\sqrt{ }} 3.1$ and $\mathrm{Ca}_{\mathrm{V}} 3.2$ were detected in rat $\mathrm{MC}[12,13]$ and $\mathrm{Ca}_{\mathrm{V}} 3.2$ is expressed in human MC[12, 13]. However, in our study, we have shown that all three TTCC isoforms (Cav3.1, Cav3.2 and $\mathrm{Ca}_{\mathrm{V}} 3.3$ ) were expressed in mouse MC. Various studies have used mibefradil and $\mathrm{TH} 1177$ as an inhibitor of TTCC in proximal tubular epithelial cells, MC and other cell types. Mibefradil has a 10-fold selectivity to TTCC than LTCC $[19,20]$, whereas, TH1177 may inhibit other ion channels. In prostate cancer cells, $\mathrm{TH} 1177$ inhibits proliferation by impeding the entry of $\mathrm{Ca}^{2+}$, but it does not affect calcium release from internal stores[21]. TH1177 is reported to affect a range of cation channels including TRPV5 channels[22]. Studies in rat and human MC show that the MC were sensitive to the TTCC inhibitors mibefradil and TH1177 but there was no effect seen by the LTCC inhibitor (verapamil) [12,13]. Similar sensitivity was shown in our mouse MC to mibefradil and TH1177 with no effect of verapamil. As TTCC blockers can be non-selective, to accurately understand the role of TTCC, it is important to look at the effect of the different isoforms in signaling and proliferation.

The role of $\mathrm{Ca}_{\sqrt{ }} 3.1 \mathrm{in}$ cell proliferation has been described in heart, lung and cancer cells[14, 23-26]. Human pulmonary artery myocytes express $\mathrm{Ca}_{\vee} 3.1$ and silencing of $\mathrm{Ca}_{\sqrt{ }} 3.1$ inhibits serum-induced proliferation[23]. This is consistent with studies in preadipocytes in primary culture. The level of $\mathrm{Ca}_{\mathrm{V}} 3.1 \mathrm{in}$ preadipocytes is high and is downregulated during differentiation. Knockdown of $\mathrm{Ca}_{\vee} 3.1$ or use of mibefradil inhibits preadipocyte proliferation[27]. $\mathrm{Ca}_{\mathrm{V}} 3.1$ also plays a different role in the cancer cells. Knockdown of $\mathrm{Ca}_{\mathrm{v}} 3.1$ indeed induces cell proliferation and reduces apoptosis in MCF-7 breast cancer cells. The effect was reversed by overexpression of $\mathrm{Ca}_{\sqrt{ }} 3.1$. The effect of $\mathrm{Ca}_{\mathrm{V}} 3.1$ knockdown is similar to the TTCC blocker (tarantula toxin ProTx-1). In MCF-7 cells, knockdown of $\mathrm{Ca}_{\mathrm{V}} 3.2$ did not affect proliferation or apoptosis[26]. All these studies used siRNA to transiently silence the $\mathrm{Ca}_{\mathrm{v}} 3.1$ or $\mathrm{Ca}_{\mathrm{v}} 3.2$ isoforms and evaluate their roles in proliferation. There have been no studies to date demonstrating the specific role of TTCC isoform on the MC proliferation in the kidney. TTCC inhibition experiments in rat and human MC also did not delineate the specific role of TTCC isoforms, which we have addressed in this study using CRISPR-cas9 gene editing. In our study, mouse MCs lacking either $\mathrm{Ca}_{\mathrm{V}} 3.1$ or $\mathrm{Ca}_{\mathrm{V}} 3.2$ survived and formed single-cell clones whereas $\mathrm{Ca}_{\mathrm{v}} 3.1$ and $\mathrm{Ca}_{\mathrm{V}} 3.2 \mathrm{DKO}$ clones didn't survive to carry out the western blot. This suggests that expression of either one of the TTCC isoforms is sufficient to support cell proliferation and cell survival. 
Given the wealth of evidence suggesting a role for T-type Ca channels in cell proliferation, it is surprising that knocking out each isoform individually has virtually no impact on cell proliferation. However, since the relationship between T-type Ca current and proliferation is extremely steep (see Fig. 4 in [28]), with only a small residual current being permissive for proliferation, it seems that the presence of either isoform is sufficient to allow effectively normal proliferation. The absence of both isoforms however is lethal - presumably by completely preventing cell cycle progression. On the other hand, pharmacological inhibition, with drugs showing little of no isoform selectivity, allows a graded reduction in Ca influx and hence a graded anti-proliferative effect.

MC proliferation is controlled by various regulators of the cell cycle, including PI3/AKT, Ras/MAPK, and calmodulin-dependent kinase signaling[8, 9]. These are likely to be involved in the changes seen in MC proliferation in TTCC KO clones. MAPK plays an important role in mesangioproliferative disease and inhibition of Ras/ERK1/2 by a pharmacological inhibitor or Ras antagonist reduces glomerular cell proliferation $[17,18]$. It has been shown that in rat pulmonary artery smooth muscle cells (PASMCs) stimulation with insulin growth factor - 1 (IGF-1) induces Ca 3.1 expression, and the level was decreased when treated with both PI3K and MEK inhibitor[14]. PASMCs treated with constitutively active AKT increase basal $\mathrm{Ca}_{\mathrm{V}} 3.1$ expression more than with constitutively active MEK treatment, suggesting upregulation of $\mathrm{Ca}_{\mathrm{V}} 3.1$ is via AKT signaling[14]. Similarly, $\mathrm{Ca}_{\mathrm{v}} 3.1$ is highly expressed in prostate cancer tissue. Knockdown of $\mathrm{Ca}_{\mathrm{V}} 3.1$ in PC-3 and Dol45 cells suppressed cell proliferation by inhibiting the transition of cells to $\mathrm{G} 1 / \mathrm{S}$ phase. The $\mathrm{Ca}_{\mathrm{V}} 3.1$ knockdown in the cancer cells decreases phosphorylated AKT (pAKT) protein which was recovered by ectopic AKT expression[25]. Furthermore, idiopathic pulmonary arterial hypertension cells (iPAH) are more proliferative than cells from control pulmonary arteries. TTCC blocker TTA-A2 reduced the proliferation of iPAH cells by delaying the S/G2 transition. TTA-A2 induces PAKT but not pERK1/2 or phosphorylated P38, suggesting the proliferation of $\mathrm{PAAH}$ is diverted to AKT signaling[24]. All these studies suggest that the $\mathrm{Ca}_{\mathrm{V}} 3.1$-dependent regulation of proliferation is mostly via AKT signalling.

The present results in mouse $\mathrm{MC}$ reveal a significant role for $\mathrm{Ca}_{\mathrm{V}} 3.1$ in the stimulated phosphorylation of ERK1/2 with no such role for $\mathrm{Ca}_{\mathrm{V}} 3$ 3.2. The effects of both Cav3.1 and 3.2 SKO on MC proliferation were much more subtle. $\mathrm{Ca}_{\mathrm{V}} 3.1 \mathrm{SKO}$ cells without $\mathrm{pERK} 1 / 2$ responses were slightly but not profoundly hypoproliferative. This may be explained by compensatory changes in the SKO cells to amplify pERK1/2independent proliferative signaling. Similarly, TTCC inhibitors were effective in reducing proliferation in $\mathrm{Ca}_{\mathrm{V}} 3.1$ SKO cells that already had impaired pERK1/2 responses. This implies that the $\mathrm{pERK} 1 / 2$ pathway actions of these agents may not be the mechanism of their anti-proliferative actions. TTCC activity may be coupled to proliferation by multiple pathways. Moreover, these small molecule TTCC inhibitors likely have a range of actions on cation channels, including inhibition of TRP channels[22]. These off-target effects are another possible explanation for their anti-proliferative actions.

\section{Conclusion}


Treatment with the non-selective TTCC inhibitors, mibefradil and TH1177 or deletion of $\mathrm{Ca}_{\mathrm{V}} 3.1$ in mouse $\mathrm{MC}$ prevents the stimulated phosphorylation of ERK1/2 but deletion of $\mathrm{Ca}_{\mathrm{v}} 3.2$ does not. Deletion of either isoform alone has a limited impact on cell proliferation whereas treatment with mibefradil and $\mathrm{TH} 1177$ is highly anti-proliferative. Deletion of both $\mathrm{Ca}_{\mathrm{v}} 3.1$ and $\mathrm{Ca}_{\mathrm{v}} 3.2$ results complete inhibition of cell proliferation and cell death. This is consistent with a previous report from our group showing reduced pERK1/2 immuno-localisation in the glomeruli of TH1177-treated animals with Thy 1 nephritis[12]. This study justifies further work using genetic models in mice to further delineate the roles of TTCC in mesangial cell biology and the pathology of mesangioproliferative CKD. Use of conditional and cellspecific KO should allow these ideas to be tested. Isoform-selective TTCC inhibitors may also help to dissect the actions seen and warrant further study as potential therapeutics in mesangioproliferative glomerular disease.

\section{Abbreviations}

MC - Mesangial cell

TTCC: T-type calcium channel

LTCC: L- type calcium channel

CRISPR: Clustered regularly interspaced short palindromic repeats

cas9: CRISPR associated protein 9

KO: Knockout

ECM: Extracellular matrix

CKD: Chronic kidney disease

$\lg A$ : immunoglobulin A

FBS: Fetal bovine serum

PDGF: Platelet derived growth factor

TGF- $\beta 1$ : Transforming growth factor - beta 1

RNA: Ribonucleic acid

DNA: Deoxyribonucleic acid

cDNA: Complementary deoxyribonucleic acid

RT-PCR: Reverse transcriptase- Polymerase chain reaction 
ANOVA: analysis of variance

\section{Declarations}

\section{Ethics approval and consent to participate}

Not applicable

\section{Consent for publication}

Not applicable

\section{Availability of data and materials}

Data from this study will be available from the corresponding author on reasonable request.

\section{Competing interests}

$\mathrm{BMH}$ is an employee and stock holder of Travere Therapeutics. CCS has received consulting fees from Novartis Pharmaceuticals and speaker fees from Napp Pharmaceuticals. MJS and SPSP declare no potential conflict of interest

\section{Funding}

This work was funded by a project grant from Kidney Research UK (RP39/2014) and from the British Heart Foundation (RG/12/4/29426)

\section{Author contributions}

SPSP undertook the experimental work, helped with data interpretation and read, edited and approved the final manuscript. BMH, CCS and MJS conceived and designed the study, helped with data interpretation and read, edited and approved the final manuscript.

\section{Acknowledgements}

We would like to acknowledge the help of Mr Mazhar Noor for managing the laboratory and training staff in key scientific procedures.

\section{References}

1. Kurihara H, Sakai T: Cell biology of mesangial cells: the third cell that maintains the glomerular capillary. Anatomical science international 2017, 92(2):173-186.

2. Pabst R, Sterzel RB: Cell renewal of glomerular cell types in normal rats. An autoradiographic analysis. Kidney international 1983, 24(5):626-631. 
3. Pesce CM, Striker LJ, Peten E, Elliot SJ, Striker GE: Glomerulosclerosis at both early and late stages is associated with increased cell turnover in mice transgenic for growth hormone. Lab Invest 1991, 65(5):601-605.

4. Floege J, Burns MW, Alpers CE, Yoshimura A, Pritzl P, Gordon K, Seifert RA, Bowen-Pope DF, Couser WG, Johnson RJ: Glomerular cell proliferation and PDGF expression precede glomerulosclerosis in the remnant kidney model. Kidney international 1992, 41(2):297-309.

5. Floege J, Johnson RJ, Gordon K, lida H, Pritzl P, Yoshimura A, Campbell C, Alpers CE, Couser WG: Increased synthesis of extracellular matrix in mesangial proliferative nephritis. Kidney international 1991, 40(3):477-488.

6. Feng X, Wu C, Yang M, Liu Q, Li H, Liu J, Zhang Y, Hao Y, Kang L, Zhang Y et al: Role of PI3K/Akt signal pathway on proliferation of mesangial cell induced by HMGB1. Tissue \& cel/ 2016, 48(2):121125.

7. Gilbert RE, Kelly DJ, McKay T, Chadban S, Hill PA, Cooper ME, Atkins RC, Nikolic-Paterson DJ: PDGF signal transduction inhibition ameliorates experimental mesangial proliferative glomerulonephritis. Kidney international 2001, 59(4):1324-1332.

8. Cove-Smith A, Hendry BM: The regulation of mesangial cell proliferation. NephronExperimental nephrology 2008, 108(4):e74-79.

9. Schocklmann HO, Lang S, Sterzel RB: Regulation of mesangial cell proliferation. Kidney international 1999, 56(4):1199-1207.

10. McCleskey EW, Fox AP, Feldman D, Tsien RW: Different types of calcium channels. The Journal of experimental biology 1986, 124:177-190.

11. Orth SR, Nobiling R, Bonisch S, Ritz E: Inhibitory effect of calcium channel blockers on human mesangial cell growth: evidence for actions independent of L-type Ca2+ channels. Kidney internationa/ 1996, 49(3):868-879.

12. Cove-Smith A, Mulgrew CJ, Rudyk O, Dutt N, McLatchie LM, Shattock MJ, Hendry BM: Antiproliferative actions of T-type calcium channel inhibition in Thy1 nephritis. The American journal of pathology 2013, 183(2):391-401.

13. Mulgrew CJ, Cove-Smith A, McLatchie LM, Brooks G, Shattock MJ, Hendry BM: Inhibition of human mesangial cell proliferation by targeting T-type calcium channels. NephronExperimental nephrology 2009, 113(2):e77-88.

14. Pluteanu F, Cribbs LL: Regulation and function of Cav3.1 T-type calcium channels in IGF-I-stimulated pulmonary artery smooth muscle cells. Am J Physiol Cell Physiol 2011, 300(3):C517-525.

15. Thuesen AD, Andersen K, Lyngso KS, Burton M, Brasch-Andersen C, Vanhoutte PM, Hansen PBL: Deletion of T-type calcium channels Cav3.1 or Cav3.2 attenuates endothelial dysfunction in aging mice. Pflugers Arch 2018, 470(2):355-365.

16. Lu F, Chen H, Zhou C, Liu S, Guo M, Chen P, Zhuang H, Xie D, Wu S: T-type Ca2+ channel expression in human esophageal carcinomas: a functional role in proliferation. Cell calcium 2008, 43(1):49-58. 
17. Bokemeyer D, Panek D, Kramer HJ, Lindemann M, Kitahara M, Boor P, Kerjaschki D, Trzaskos JM, Floege J, Ostendorf T: In vivo identification of the mitogen-activated protein kinase cascade as a central pathogenic pathway in experimental mesangioproliferative glomerulonephritis. J Am Soc Nephro/ 2002, 13(6):1473-1480.

18. Clarke HC, Kocher HM, Khwaja A, Kloog Y, Cook HT, Hendry BM: Ras antagonist farnesylthiosalicylic acid (FTS) reduces glomerular cellular proliferation and macrophage number in rat thy-1 nephritis. $J$ Am Soc Nephrol 2003, 14(4):848-854.

19. Martin RL, Lee JH, Cribbs LL, Perez-Reyes E, Hanck DA: Mibefradil block of cloned T-type calcium channels. J Pharmacol Exp Ther 2000, 295(1):302-308.

20. Griffin KA, Picken M, Bakris GL, Bidani AK: Comparative effects of selective T- and L-type calcium channel blockers in the remnant kidney model. Hypertension 2001, 37(5):1268-1272.

21. Haverstick DM, Heady TN, Macdonald TL, Gray LS: Inhibition of human prostate cancer proliferation in vitro and in a mouse model by a compound synthesized to block Ca2+ entry. Cancer Res 2000, 60(4):1002-1008.

22. Landowski CP, Bolanz KA, Suzuki Y, Hediger MA: Chemical inhibitors of the calcium entry channel TRPV6. Pharm Res 2011, 28(2):322-330.

23. Rodman DM, Harral J, Wu S, West J, Hoedt-Miller M, Reese KA, Fagan K: The low-voltage-activated calcium channel CAV3.1 controls proliferation of human pulmonary artery myocytes. Chest 2005 , 128(6 Suppl):581s-582s.

24. Sankhe S, Manousakidi S, Antigny F, Arthur Ataam J, Bentebbal S, Ruchon Y, Lecerf F, Sabourin J, Price L, Fadel E et al: T-type $\mathrm{Ca}(2+)$ channels elicit pro-proliferative and anti-apoptotic responses through impaired PP2A/Akt1 signaling in PASMCs from patients with pulmonary arterial hypertension. Biochim Biophys Acta Mol Cell Res 2017, 1864(10):1631-1641.

25. Hu S, Li L, Huang W, Liu J, Lan G, Yu S, Peng L, Xie X, Yang L, Nian Y et al: CAV3.1 knockdown suppresses cell proliferation, migration and invasion of prostate cancer cells by inhibiting AKT. Cancer Manag Res 2018, 10:4603-4614.

26. Ohkubo T, Yamazaki J: T-type voltage-activated calcium channel Cav3.1, but not Cav3.2, is involved in the inhibition of proliferation and apoptosis in MCF-7 human breast cancer cells. Int J Onco/2012, 41(1):267-275.

27. Oguri A, Tanaka T, lida H, Meguro K, Takano H, Oonuma H, Nishimura S, Morita T, Yamasoba T, Nagai $\mathrm{R}$ et al: Involvement of CaV3.1 T-type calcium channels in cell proliferation in mouse preadipocytes. Am J Physiol Cell Physiol 2010, 298(6):C1414-1423.

28. Gray LS, Perez-Reyes E, Gomora JC, Haverstick DM, Shattock M, McLatchie L, Harper J, Brooks G, Heady T, Macdonald TL: The role of voltage gated T-type Ca2+ channel isoforms in mediating "capacitative" Ca2+ entry in cancer cells. Cell Calcium 2004, 36(6):489-497.

\section{Figures}




\section{a: Mibefradil}
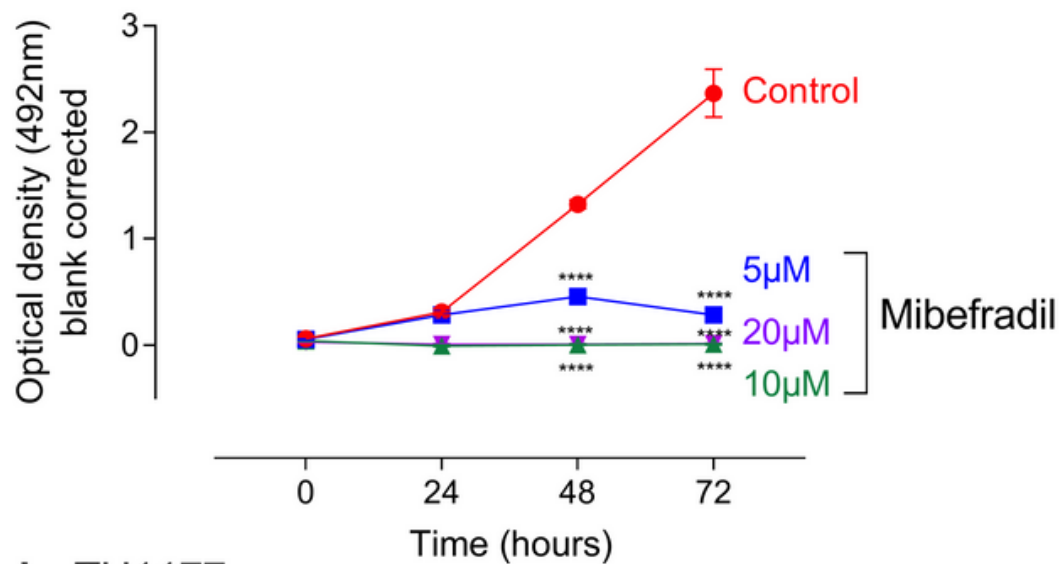

b: $\mathrm{TH} 1177$

Time (hours)
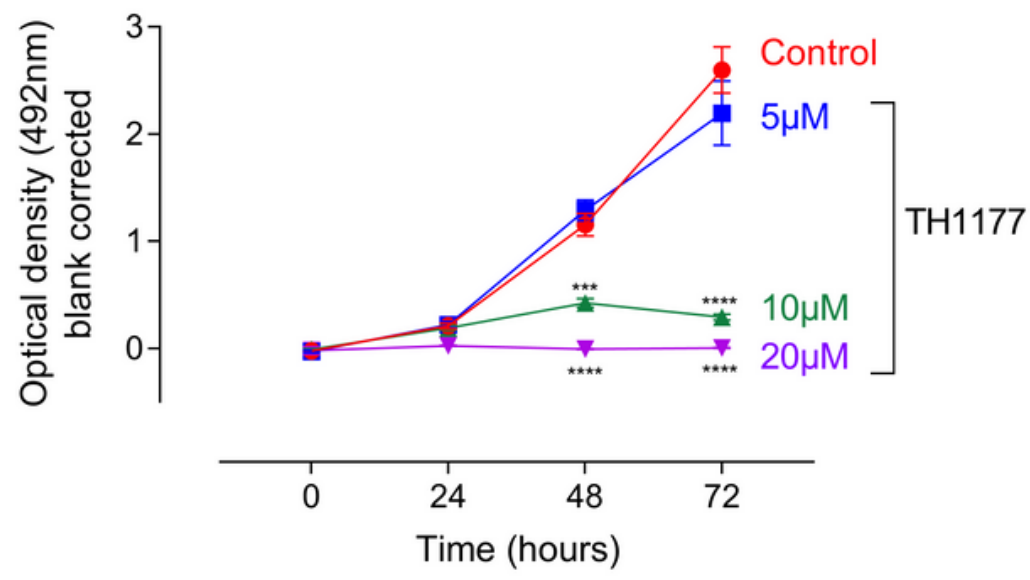

\section{c: Verapamil}
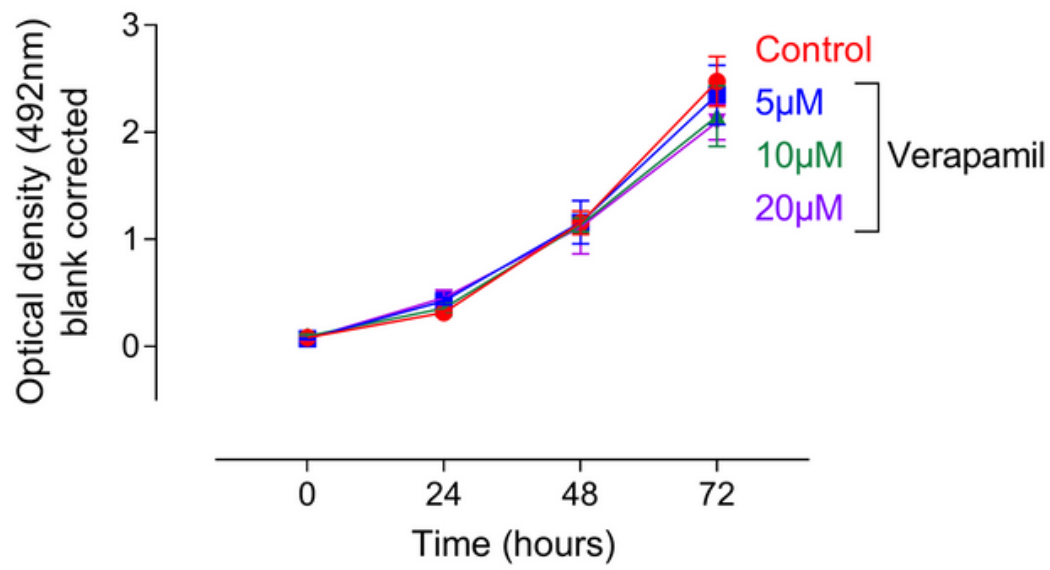

\section{Figure 1}

Modulation of Mouse mesangial cell proliferation by TTCC blockers. MES13 cells treated with TTCC blockers mibefradil (a), TH1177 (b) from 0-20 $\mu \mathrm{M}$ concentration shows dose-dependent inhibition of mesangial cell proliferation in comparison to vehicle control and $L$ type calcium channel blocker verapamil (c). The data are represented as mean $\pm S D$. $n=4,{ }^{*} * \star P<0.001$, $* \star \star \star P<0.0001$ is the comparison between the concentration to vehicle control. Two-Way ANOVA with Turkey post hoc correction. 
a

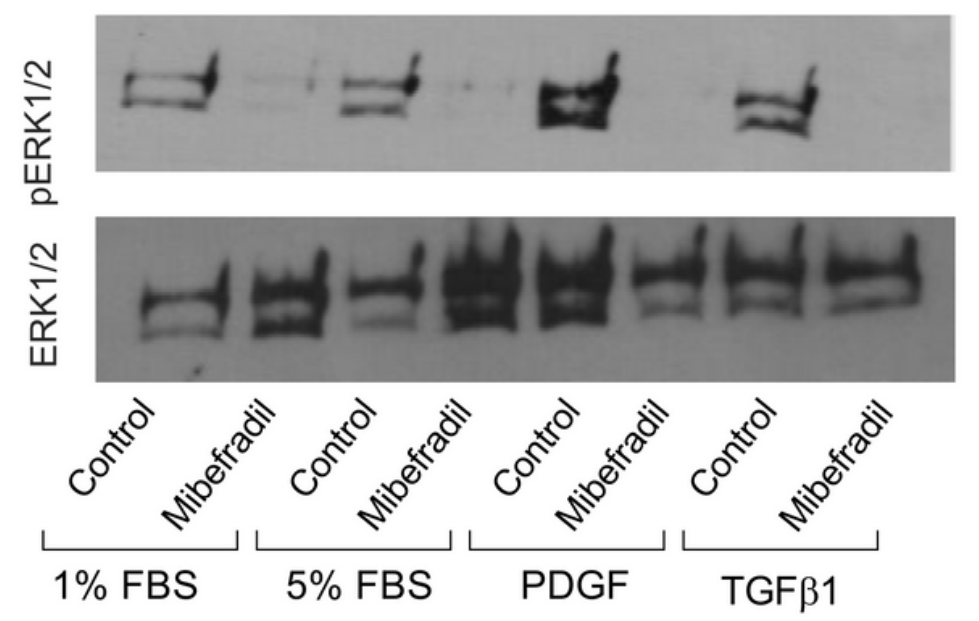

b

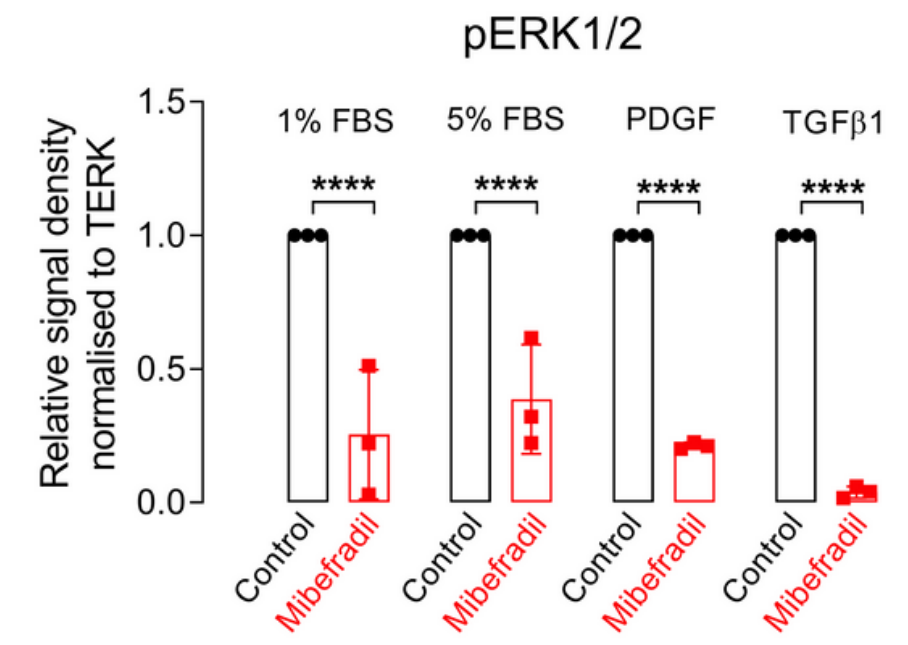

Figure 2

Mibefradil inhibits phosphorylation of ERK1/2 in the presence of 5\%, FBS, PDGF or TGFß1. A representative Western blot showing phosphorylated ERK1/2 levels in MES13 cells with and without mibefradil treatment in 1\% FBS (a) for 4 hours, in all media conditions (with $5 \%$ FBS, PDGF or TGFB1). The full-length images of Western blot are presented in Supplementary figure S5. (b) shows the mean densitometry quantification of pERK1/2 levels (normalised to total ERK1/2) in three independent experiments with MES13 cells treated with mibefradil for 4 hours and controls in a range of media conditions ( $5 \%$ FBS, PDGF or TGF $\beta 1$ ). The data are represented as mean $\pm S D, n=3, \star \star \star \star p<0.0001$, from a One-Way ANOVA with Bonferroni post hoc correction.

a
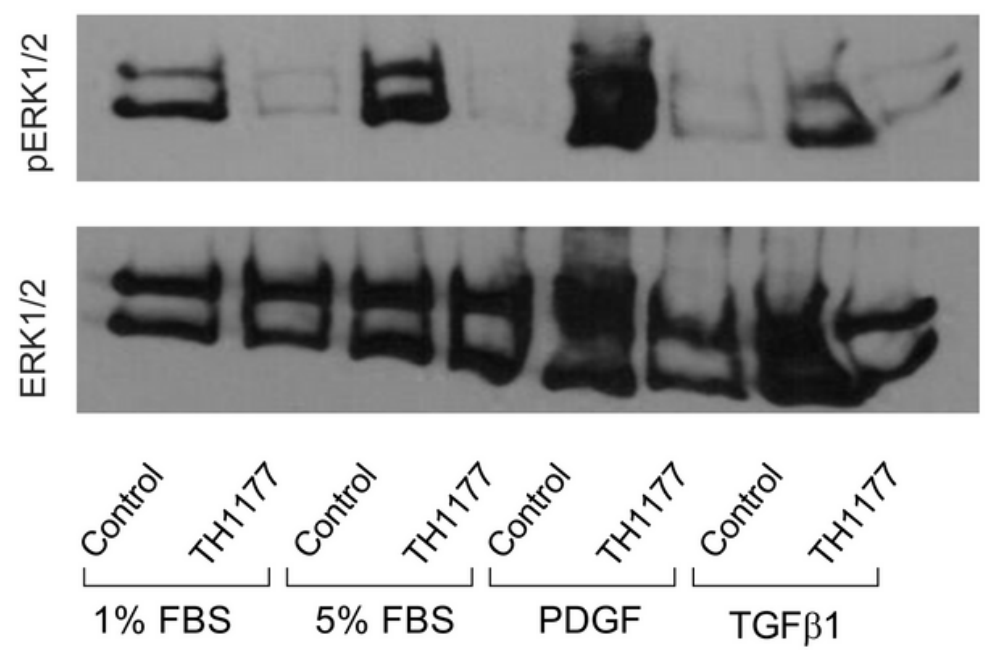

b

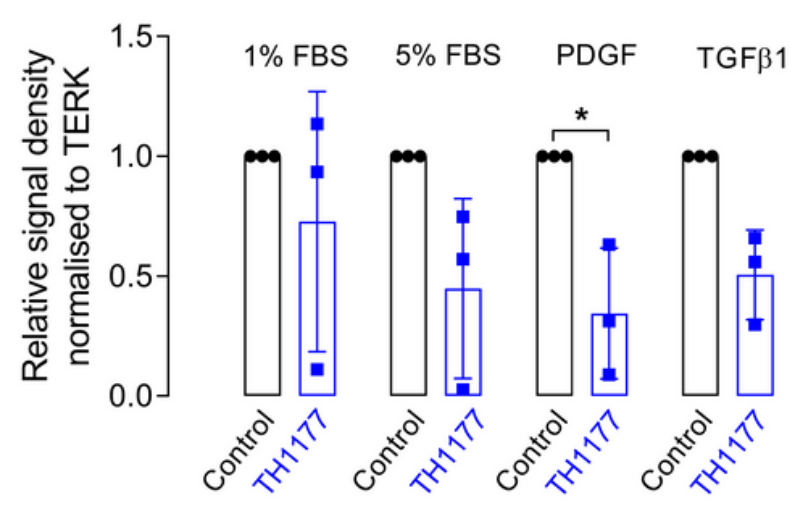




\section{Figure 3}

TH1177 inhibits phosphorylation of ERK1/2 in the presence of 5\%, FBS, PDGF or TGF 31 . (a) shows a representative Western blot showing phosphorylated ERK1/2 levels in MES13 cells with and without TH1177 treatment for 4 hours, in all media conditions (with 5\% FBS, PDGF or TGF $\beta 1$ ). The full-length images of Western blot are presented in Supplementary figure S6. (b) shows the mean densitometry quantification of pERK1/2 levels (normalised to total ERK1/2) in three independent experiments of MES13 cells treated with TH1177 for 4 hours and controls in a range of media conditions (5\% FBS, PDGF or TGF $\beta 1$ ). The data are represented as mean $\pm S D, n=3, * p<0.05$, from a One-Way ANOVA with Bonferroni post hoc correction.

a

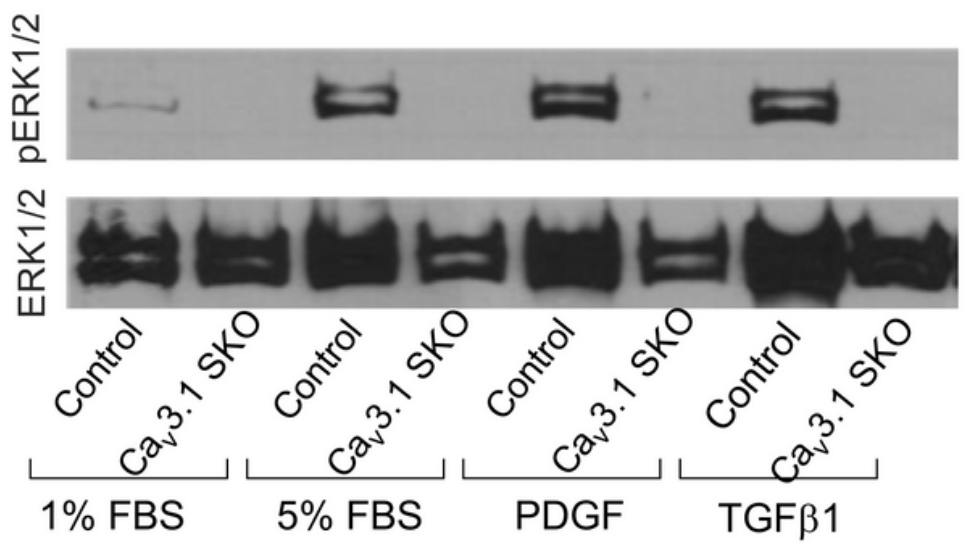

C
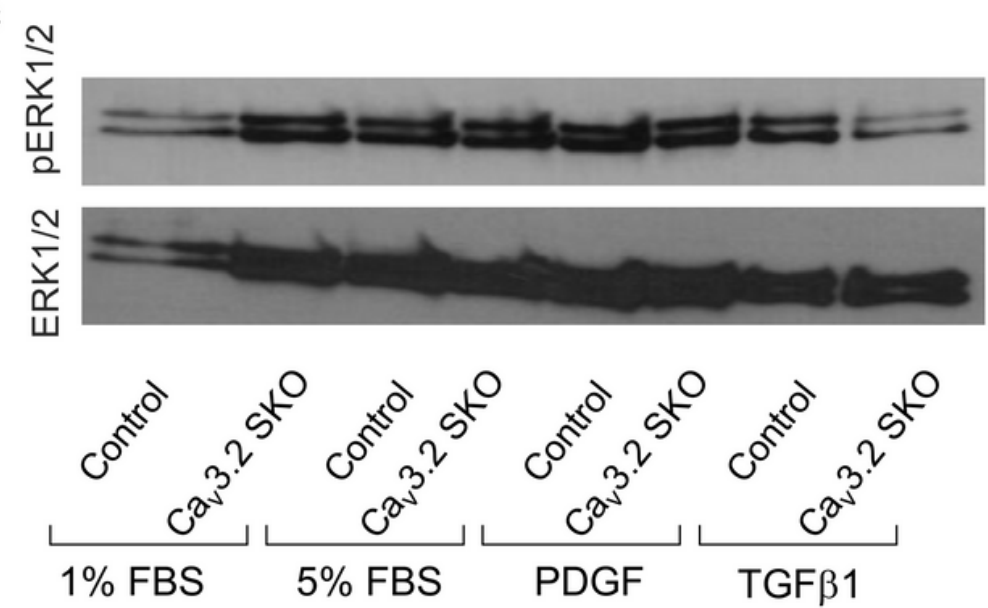

b

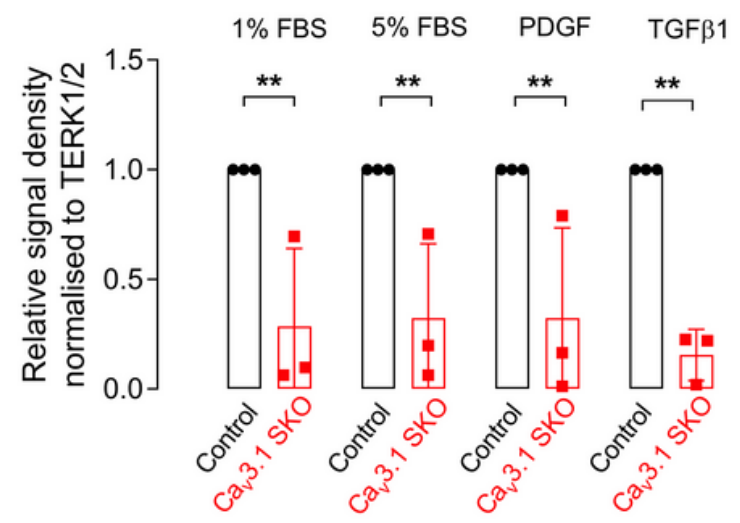

pERK1/2

d

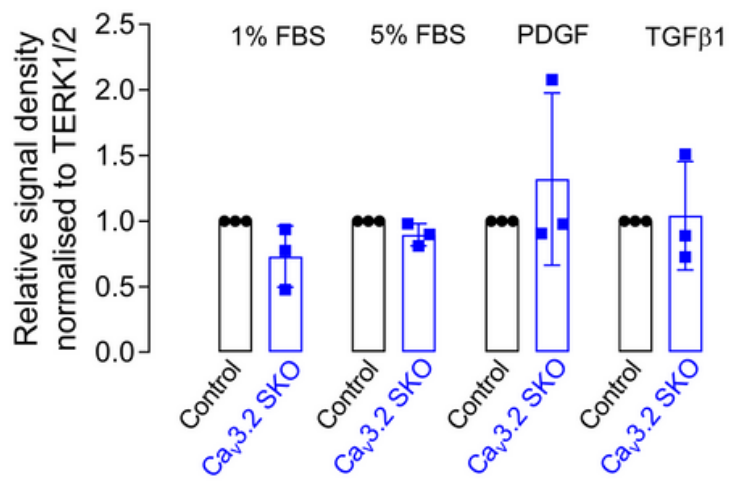

\section{Figure 4}

CaV3.1 but not CaV3.2 SKO in 5\% FBS, PDGF and TGF- $\beta 1$ inhibits phosphorylation of ERK1/2. A representative Western blot showing phosphorylated ERK1/2 levels in MES13 control cells, CaV3.1 SKO clone (a) and CaV3.2 SKO clone (c) in all media conditions (with 5\% FBS, PDGF or TGF- 31 ). The fulllength images of Western blot are presented in Supplementary figure S7. (b) shows the mean densitometry quantification of pERK1/2 levels (normalised to total ERK1/2) in three independent 
experiments of CaV3.1 SKO clones and control in a range of medium conditions (5\%FBS, PDGF or TGF$\beta 1$ ). The data are represented as mean $\pm S D, n=3,{ }^{*} p<0.05,{ }^{*} p<0.01,{ }^{* \star *} p<0.001$, from a One-way Anova with Bonferroni post hoc correction. (d) shows similar densitometry for CaV3.2 KO cells.

a: Mibefradil at $48 \mathrm{~h}$

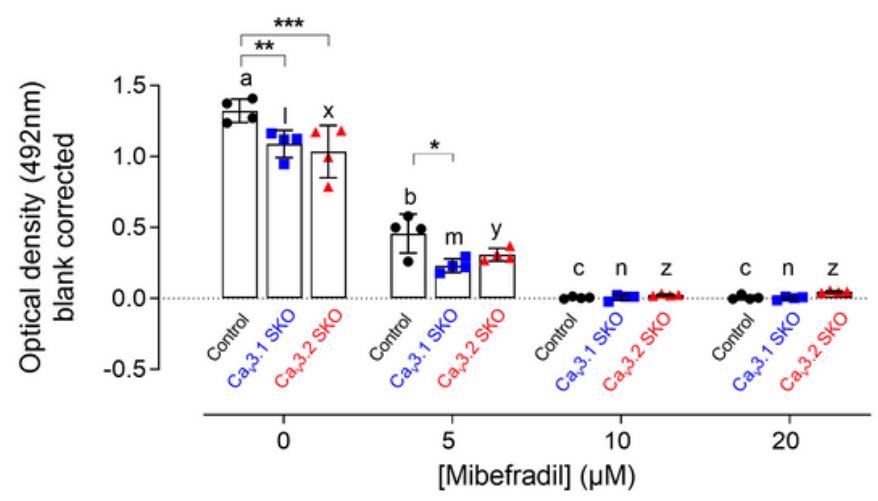

c: $\mathrm{TH} 1177$ at $48 \mathrm{~h}$

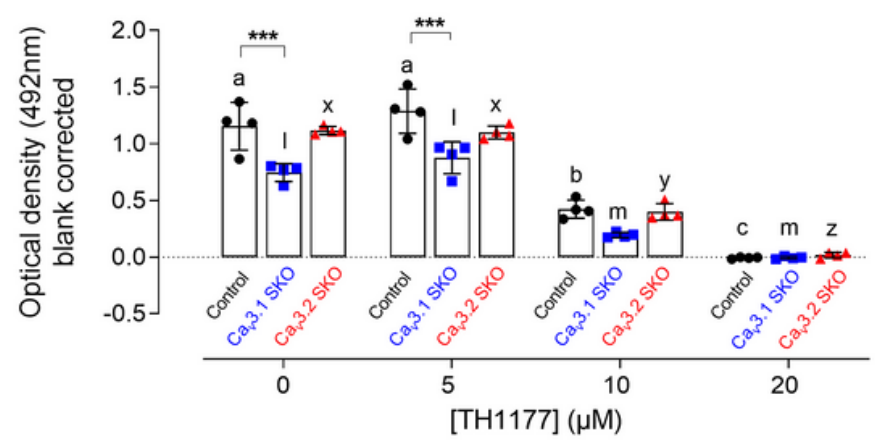

b: Mibefradil at $72 \mathrm{~h}$

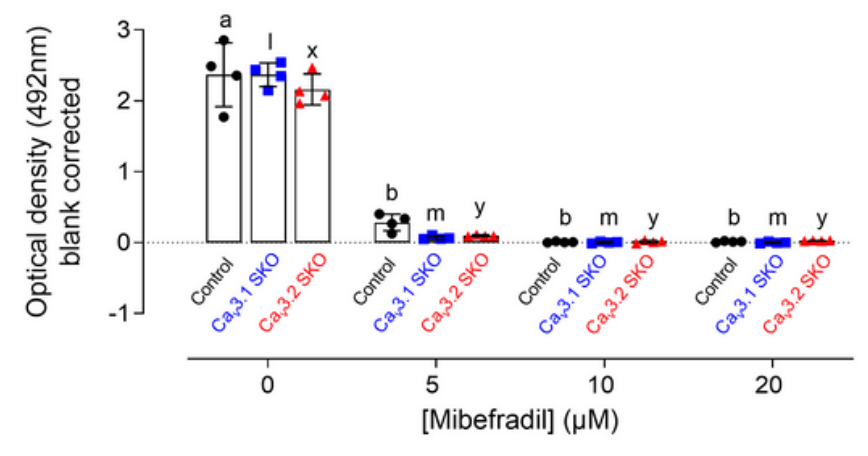

d: TH1177 at $72 \mathrm{~h}$

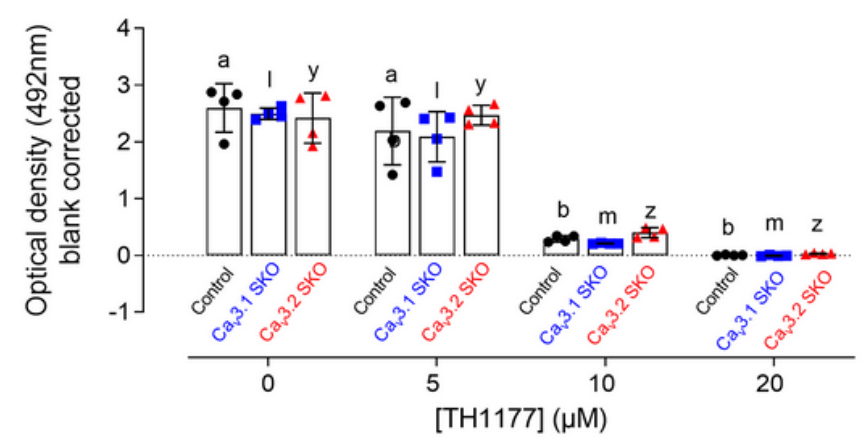

\section{Figure 5}

Modulation of CaV3.1 SKO, CaV3.2 SKO and MES13 cell proliferation by TTCC blockers Cell proliferation of the CaV3.1, CaV3.2 knockout cells after treatment with TTCC blockers: mibefradil (a-b) and TH1177 (cd) were compared to wild type control cells (MES13). Cell number was calculated by using the MTS assay in time points at 48 and $72 \mathrm{~h}$. The data are represented as mean \pm SD. Letters 'abc', 'Imn' and 'xyz' are used to denote the significance between drug concentration in control, CaV3.1 and CaV3.2 respectively. The same letter above the graphs indicates no change between the groups. Different letters above the graph indicate the significant difference between the means. The data are represented as mean $\pm S D, n=4,{ }^{*} P<0.01,{ }^{*} * \mathrm{P}<0.001$ are for the comparison between $K O$ to its respective control at each concentration. Two-Way ANOVA with Turkey post hoc correction.

\section{Supplementary Files}

This is a list of supplementary files associated with this preprint. Click to download.

- SupplementaryMaterial.pdf 